\title{
A reactivity-selectivity study of the Friedel-Crafts acetylation of 3,3'-dimethylbiphenyl and the oxidation of the acetyl derivatives
}

\author{
Salam JJ Titinchi ${ }^{1 *}$, Fadhil S Kamounah ${ }^{2}$, Hanna S Abbo ${ }^{1}$ and Ole Hammerich ${ }^{3 *}$
}

\begin{abstract}
Background: Friedel-Crafts acetylation is an important route to aromatic ketones, in research laboratories and in industry. The acetyl derivatives of 3,3'-dimethylbiphenyl (3,3'-dmbp) have applications in the field of liquid crystals and polymers and may be oxidized to the dicarboxylic acids and derivatives that are of interest in cancer treatment.

Findings: The effect of solvent and temperature on the selectivity of monoacetylation of 3,3'-dmbp by the Perrier addition procedure was studied using stoichiometric amounts of reagents. 4-Ac-3,3'-dmbp was formed almost quantitatively in boiling 1,2-dichloroethane and this is almost twice the yield hitherto reported. Using instead a

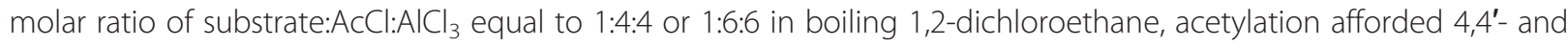
4,6'-diacetyl-3,3'-dmbp in a total yield close to $100 \%$. The acetyl derivatives were subsequently converted to the carboxylic acids by hypochlorite oxidation. The relative stabilities of the isomeric products and the corresponding $\sigma$-complexes were studied by DFT calculations and the data indicated that mono- and diacetylation followed different mechanisms.
\end{abstract}

Conclusions: Friedel-Crafts acetylation of 3,3'-dmbp using the Perrier addition procedure in boiling 1,2dichloroethane was found to be superior to other recipes. The discrimination against the 6-acetyl derivative during monoacetylation seems to reflect a mechanism including an $\mathrm{AcCl}: \mathrm{AlCl}_{3}$ complex or larger agglomerates as the electrophile, whereas the less selective diacetylations of the deactivated 4-Ac-3,3'-dmbp are suggested to include the acetyl cation as the electrophile. The DFT data also showed that complexation of intermediates and products with $\mathrm{AlCl}_{3}$ does not seem to be important in determining the mechanism.

Keywords: Friedel-Crafts reaction, 3,3'-dimethylbiphenyl, Monoacetylation, Diacetylation, Carboxylic acids, DFT calculations

\section{Findings}

The Friedel-Crafts acylation is a powerful and successful way to introduce new carbon-carbon bonds in aromatic compounds and is one of the most important one-step routes for the synthesis of aromatic ketones, in research laboratories and in the chemical and pharmaceutical industries [1-5]. Although the reaction has been known for more than 130 years it still receives attention [6-16] the recent interest being focused on the use of ionic liquids as solvents [7],

\footnotetext{
*Correspondence: stitinchi@uwc.ac.za; o.hammerich@chem.ku.dk ${ }^{1}$ Department of Chemistry, University of the Western Cape, Private Bag X17, Bellville, 7535, South Africa

${ }^{3}$ Department of Chemistry, University of Copenhagen, Universitetsparken 5, Copenhagen $\varnothing$, DK-2100, Denmark

Full list of author information is available at the end of the article
}

selectivity studies $[6,9,11,13]$, the application of solid catalysts [16], and still, mechanism details $[8,12,14,15]$. Simple aromatic hydrocarbons and methyl substituted derivatives have featured as substrates in both earlier and more recent studies of the reaction including benzenes [6,7,17-19], biphenyls and fluorene [11,13,20], naphthalenes [21-23], anthracenes [14,24,25], phenanthrenes [12,26], pyrenes [27], and chrysenes [28] and as a part of our continuing interest in FriedelCrafts acetylations [11,13,21,28-31], we now report details of the acetylation of 3,3'-dimethylbiphenyl (3,3'-dmbp). Compounds and materials derived from this building block are of particular interest in the field of molecular liquid crystals [31], polymers [32,33] and metal-complexes [34].

The literature offers only few studies of the FriedelCrafts functionalization of $3,3^{\prime}$-dmbp. In the early

\section{(C) Chemistry Central}


thirties it was reported [35] that acylation of 3,3'-dmbp with $\alpha$-naphthoyl chloride in the presence of $\mathrm{AlCl}_{3}$ resulted in the formation of 4,4'-di(1-naphthoyl)-3,3'dmbp (41\%) and to the best of our knowledge only two studies of the Friedel-Crafts acetylation of 3,3'-dmbp have appeared. Acetylation in 1,2-dichloroethane with acetic anhydride and aluminium chloride was reported [36] to give the 4-acetyl derivative (50\%) and the same product was obtained (38.5\%) when the reaction was carried out in carbon disulphide [37]. Diacetylation of $3,3^{\prime}$-dmbp has been mentioned only briefly in the literature [30]. Other electrophilic substitution reactions of $3,3^{\prime}$-dmbp include chlorination that gives a mixture of 2-, 4- and 6-chloro-3,3'-dmbp with the 4-isomer being dominating [38], bromination and iodination that lead to the 4-halo derivatives [39] and sulphonation [40] that with an excess of $98 \% \mathrm{H}_{2} \mathrm{SO}_{4}$ leads to a $52: 48$ mixture of the 4,4' -and 4,6' -disulphonic acids.

Below we report the results of an investigation of the distribution of the isomers formed by Friedel-Crafts mono- and diacetylation of 3,3'-dmbp using the Perrier addition procedure, that is the addition of the hydrocarbon to the preformed acetyl chloride-aluminium chloride complex. The study included the effect of solvent and temperature on yields and product distribution. The selectivity of the mono- and diacetylation processes is discussed using theoretical DFT data for the relative stability of the isomeric products and the intermediate $\sigma$ complexes. The further oxidation of the resulting monoand diketones with hypochlorite to the corresponding carboxylic acids is reported as well.

\section{Synthesis of 3,3'-dimethylbiphenyl}

The starting material, 3,3'-dmbp, was synthesized by two different methods. Ullman coupling of 3-iodotoluene yielded $60 \%$ of a high purity product $(99.5 \%$ glc), while deamination of $4,4^{\prime}$-diamino-3,3'-dmbp resulted in a somewhat higher yield, $84 \%$. However the latter procedure is slightly more expensive due to the high cost of starting materials.

\section{The acetylation products}

The products and yields are summarized in Tables 1 and 2. The abbreviations used for the mono and diketones are $\mathrm{x}-\mathrm{Ac}$ and $\mathrm{x}, \mathrm{y}^{\prime}$-diAc, respectively, where $\mathrm{x}$ and $\mathrm{y}^{\prime}$ refer to the acetylated positions of the two phenyl rings. The route for the synthesis of the acetyl isomer and the corresponding carboxylic acids is depicted in Scheme 1.

As seen from Table 1 acetylation of $3,3^{\prime}-\mathrm{dmbp}$ at $25^{\circ} \mathrm{C}$ and $45^{\circ} \mathrm{C}$ using equimolar amounts of $3,3^{\prime}-\mathrm{dmbp}, \mathrm{AcCl}$ and $\mathrm{AlCl}_{3}$ in 1,2-dichloroethane, carbon disulfide and nitromethane gave the 4-acetyl isomer, 4-Ac, exclusively in yields in the 50-60\% range. At higher temperature, that is at the boiling point of the reaction mixture, 4-Ac was
Table 1 Results from Friedel-Crafts acetylation of 3,3'dimethylbiphenyl using the Perrier addition procedure ${ }^{a}$

\begin{tabular}{lllll}
\hline Run No & Solvent & Temp $\left({ }^{\circ} \mathrm{C}\right)$ & Yield (\%) & $\begin{array}{l}\text { Isomer distribution } \\
\text { (\%) 4-Ac }\end{array}$ \\
\hline 1 & $\mathrm{ClCH}_{2} \mathrm{CH}_{2} \mathrm{Cl}$ & 25 & 56.5 & 100 \\
2 & $\mathrm{CS}_{2}$ & 25 & 55.1 & 100 \\
3 & $\mathrm{CH}_{3} \mathrm{NO}_{2}$ & 25 & 57.5 & 100 \\
4 & $\mathrm{ClCH}_{2} \mathrm{CH}_{2} \mathrm{Cl}$ & 45 & 51.9 & 100 \\
5 & $\mathrm{CS}_{2}$ & 45 & 60.8 & 100 \\
6 & $\mathrm{CH}_{3} \mathrm{NO}_{2}$ & 45 & 47.2 & 100 \\
\hline
\end{tabular}

a The 3,3'-dmbp:AcCl: $\mathrm{AlCl}_{3}$ molar ratio was 1:1:1 and the reaction time was $3 \mathrm{~h}$.

still the only ketone isolated after work-up (Table 2) and in 1,2-dichloroethane the yield had now increased to almost $100 \%$ (run no 8 ). This is a considerable improvement over the yield reported earlier (50\%) resulting from acetylation at $50^{\circ} \mathrm{C}$ with acetic anhydride in the same solvent [36]. In chlorobenzene, the 4-Ac (58.6\%) was accompanied by the formation of 4-chloroacetophenone as a byproduct in about $18 \%$ yield formed by acetylation of the solvent. In boiling nitromethane the yield was only $11.8 \%$ and the reaction was accompanied by the formation of a dark polymeric material. The low yield obtained in nitromethane is not unusual; it was observed also in previous studies of the acetylation of 4,4'-dimethylbiphenyl [11] and of $9 \mathrm{H}$-fluorene [13]. When the reaction was carried out in boiling nitrobenzene acetylated products could only be detected in trace amounts. Probably the high temperature (bp. $211^{\circ} \mathrm{C}$ ) in this latter case was causing degradation of substrate, intermediates or products.

When acetylation was carried out in boiling 1,2dichloroethane with an excess of $\mathrm{AcCl}$ and $\mathrm{AlCl}_{3}$ (the

Table 2 Results from Friedel-Crafts acetylation of 3,3'dimethylbiphenyl in the boiling reaction mixture using the Perrier addition procedure ${ }^{a}$

\begin{tabular}{|c|c|c|c|c|c|c|}
\hline \multirow{2}{*}{$\begin{array}{l}\text { Run } \\
\text { No }\end{array}$} & \multirow[t]{2}{*}{ Solvent } & \multirow{2}{*}{$\begin{array}{l}\mathrm{Bp}^{\mathrm{b}} \\
\left({ }^{\circ} \mathrm{C}\right)\end{array}$} & \multirow{2}{*}{$\begin{array}{l}\text { Yield } \\
(\%)\end{array}$} & \multicolumn{3}{|c|}{ Isomer distribution (\%) } \\
\hline & & & & 4-Ac & 4,4'-diAc & 4,6'-diAc \\
\hline 7 & $\mathrm{CH}_{2} \mathrm{Cl}_{2}$ & 40 & 68.9 & 100 & -1 & - \\
\hline 8 & $\mathrm{ClCH}_{2} \mathrm{CH}_{2} \mathrm{Cl}$ & 84 & 96.5 & 100 & 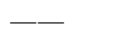 & 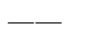 \\
\hline 9 & $\mathrm{Cl}_{2} \mathrm{CHCHCl}_{2}$ & 147 & 68.2 & 100 & - - & - \\
\hline 10 & $\mathrm{C}_{6} \mathrm{H}_{5} \mathrm{Cl}^{\mathrm{c}}$ & 131 & 58.6 & 100 & - & - \\
\hline 11 & $\mathrm{CS}_{2}$ & 46 & 55.4 & 100 & - & -- \\
\hline 12 & $\mathrm{CH}_{3} \mathrm{NO}_{2}^{\mathrm{d}}$ & 101 & 11.8 & 100 & - & - - \\
\hline 13 & $\mathrm{C}_{6} \mathrm{H}_{5} \mathrm{NO}_{2}^{\mathrm{d}}$ & 211 & Trace & Trace & - & - - \\
\hline 14 & $\mathrm{ClCH}_{2} \mathrm{CH}_{2} \mathrm{Cl}^{\mathrm{e}}$ & 84 & 99.9 & 1.6 & 43.3 & 55.1 \\
\hline 15 & $\mathrm{ClCH}_{2} \mathrm{CH}_{2} \mathrm{Cl}^{f}$ & 84 & 92.4 & - & 37.6 & 62.4 \\
\hline
\end{tabular}

${ }^{a}$ The 3,3'-dmbp:AcCl:AlCl 3 molar ratio was 1:1:1 unless otherwise stated and the reaction time was $23 \mathrm{~h} .{ }^{\mathrm{b}}$ Boiling point of the neat solvent. ${ }^{\mathrm{c}}$ In addition 4-chloroacetophenone was formed in $\sim 20 \%$ yield. ${ }^{d}$ The major products were dark colored polymeric materials and other unidentified compounds. ${ }^{\mathrm{e}}$ The 3,3'-dmbp:AcCl: $\mathrm{AlCl}_{3}$ molar ratio was 1:4:4. ${ }^{\mathrm{f}}$ The 3,3'-dmbp:AcCl: $\mathrm{AlCl}_{3}$ molar ratio was $1: 6: 6$ 

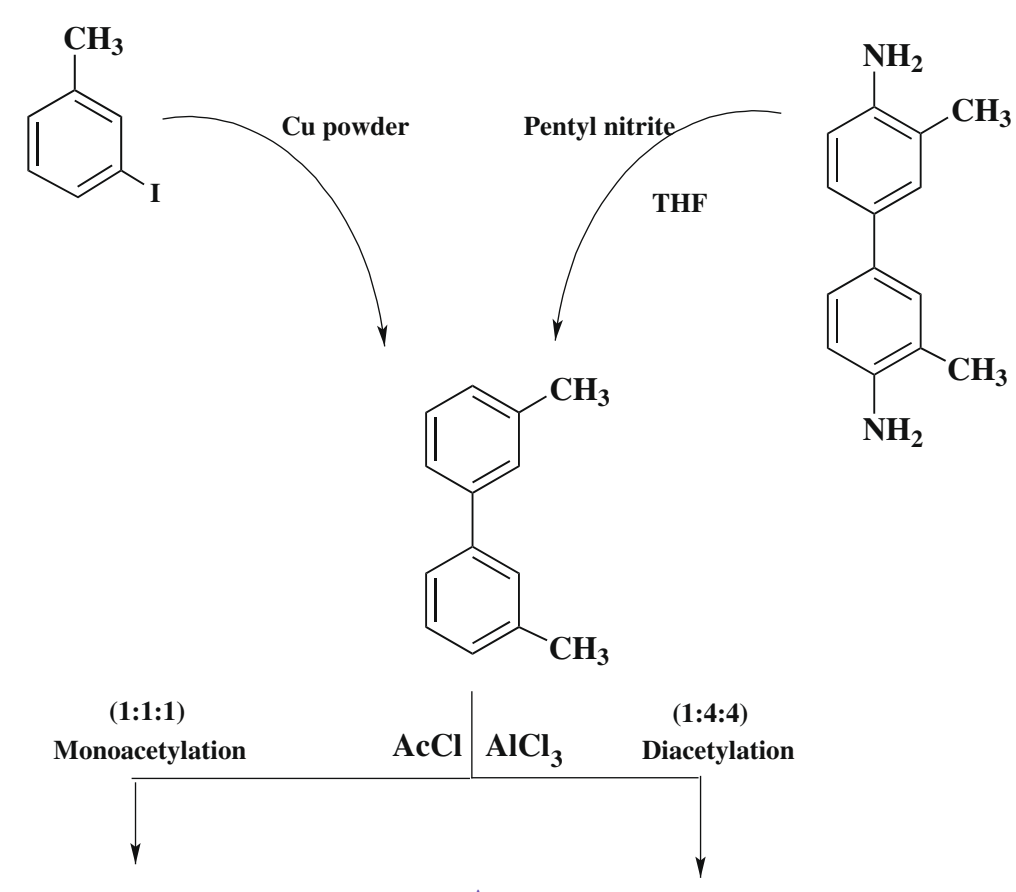<smiles>Cc1cccc(-c2ccc(C(C)(C)C)c(C)c2)c1</smiles><smiles>Cc1cc(-c2ccc(C(C)(C)C)c(C)c2)ccc1C(C)(C)C</smiles><smiles>Cc1ccc(C#N)c(-c2ccc(C(C)(C)C)c(C)c2)c1</smiles><smiles>[Y]1CCCC1</smiles><smiles></smiles><smiles></smiles><smiles>Cc1cccc(-c2ccc(C(=O)O)c(C)c2)c1</smiles><smiles>Cc1cc(-c2ccc(C(=O)O)c(C)c2)ccc1C(=O)O</smiles><smiles>Cc1ccc(C(=O)O)c(-c2ccc(C(=O)O)c(C)c2)c1</smiles>

Scheme 1 Synthesis route of the ketones and carboxylic acids.

molar ratio 3,3'-dmbp: $\mathrm{AcCl}: \mathrm{AlCl}_{3}$ equal to $1: 4: 4$ or $1: 6: 6)$, and conditions that are otherwise the same, a mixture of $4,4^{\prime}$ - and $4,6^{\prime}$-diAc in a total yield close to $100 \%$ was obtained with the relative yield of the $4,6^{\prime}$-isomer increasing slightly with increasing amounts of the $\mathrm{AcCl}$ : $\mathrm{AlCl}_{3}$ mixture (run no 14 and 15).

Thus, similarly to what has been observed earlier $[36,37]$ we find that acetylation of $3,3^{\prime}$-dmbp takes place 
Table 3 Total energies, Gibbs free energies (298 K), and structural properties for 3,3'-dimethylbiphenyl and the monoacetyl isomers, $x$-Ac

\begin{tabular}{|c|c|c|c|c|c|}
\hline Substituent & Total energy $E$ (a.u.) & $G_{298}$ (a.u.) & $\begin{array}{l}\mathrm{G}_{298} \text { relative to } \\
5-\mathrm{Ac}\left(\mathrm{kJ} \mathrm{mol}^{-1}\right)\end{array}$ & $\theta^{\mathrm{a}}$ (degrees) & $\varphi^{\mathrm{b}}$ (degrees) \\
\hline None & -541.963044 & -541.768297 & - & 38.7 & - \\
\hline $2-A c$ & -694.601204 & -694.371990 & 33.7 & 49.1 & 60.8 \\
\hline $4-A c$ & -694.610042 & -694.380270 & 12.0 & 37.3 & 0.2 \\
\hline $5-A c$ & -694.612983 & -694.384835 & 0 & 39.0 & 0.7 \\
\hline $6-A c$ & -694.604265 & -694.376276 & 22.5 & 54.4 & 31.3 \\
\hline
\end{tabular}

Results from DFT B3LYP 6-31 G(d,p) calculations. ${ }^{a}$ Dihedral angle between the two benzene rings taken as the average of the C2-C1-C1'-C6' and C6-C1-C1'-C2' dihedral angles. ${ }^{b}$ Dihedral angle between the carbonyl group and the benzene ring to which it is attached taken as the $C_{\mathrm{Ar}}-\mathrm{C}_{\mathrm{Ar}}-\mathrm{C}=\mathrm{O}$ dihedral angle.

in the 4-position and the substitution pattern we observe for diacetylation, $4,4^{\prime}$-and $4,6^{\prime}$-, is the same as that reported earlier for sulfonation [40].

\section{The spectral data}

The ${ }^{1} \mathrm{H}$ NMR spectral data of the acetyl derivatives illustrate that the chemical shift of the methyl protons could be used as an indication of the position of substitution of an acetyl or a methyl group linked to the aromatic rings $[30,41,42]$. Analysis of the ${ }^{1} \mathrm{H}$ NMR data showed that the methyl protons chemical shifts $\left(\mathrm{\delta CH}_{3}\right)$ for all the three isomers are shifted downfield by $0.15 \mathrm{ppm}$ compared to the methyl protons in the parent compound. This confirms that the acetyl group is situated ortho to the methyl group, whereas the $\delta \mathrm{CH}_{3}$ for the second ring in 4,6'-diAc-3,3'dmbp remains almost unaffected $(0.49 \mathrm{ppm})$ as it is far from the methyl group. The results obtained from the ${ }^{1} \mathrm{H}$ NMR are in agreement with the methyl protons chemical shifts $\left(\mathrm{\delta CH}_{3}\right)$ in toluene viz. the $\delta \mathrm{CH}_{3}$ being shifted downfield from 2.34 to $2.85 \mathrm{ppm}$ on substitution of an acetyl group ortho to the methyl group, while for meta- and parasubstitution, the values are 2.27 and $2.52 \mathrm{ppm}$, respectively [43].

The IR spectroscopy data further supports the positional assignment. An intense absorption band of the $\mathrm{C}=\mathrm{O}$ stretching vibration of the acetyl group appeared at 1685$1650 \mathrm{~cm}^{-1}$, which elaborate a carbonyl group sterically hindered by the adjacent tolyl or methyl groups. The carbonyl band shifted to a lower wave number in comparison to acetophenone $\left(1690 \mathrm{~cm}^{-1}\right)$ [44]. In fact, the assignment is in good agreement with the expectation of the orientation during the acetylation reaction due to the directing effect of the methyl and tolyl substituents.

The mass spectra also support the structural assignment by existence of the molecular ion peak $[\mathrm{M}]^{+}$. The breakdown of the two monoacetyl isomers under electron impact follows almost the same mass fragmentation pathways. The major fragment ions observed in the mass spectra were $\left[\mathrm{M}-\mathrm{CH}_{3}\right]^{+},\left[\mathrm{M}-\mathrm{COCH}_{3}\right]^{+},\left[\mathrm{M}-\left(\mathrm{CH}_{3}+\mathrm{COCH}_{3}\right)\right]^{+},\left[\mathrm{PhCH}_{3}\right]^{+}$, $\left[\mathrm{C}_{6} \mathrm{H}_{4}\right]^{+}$and $\left[\mathrm{COCH}_{3}\right]^{+}$.

\section{The relative stability of the products}

It is well known that the ketones resulting from FriedelCrafts acetylations exist in the reaction mixtures as the $\mathrm{AlCl}_{3}$ complexes $[5,7,25,45]$ and for that reason the discussion below of the relative stability of the products includes not only the mono- and diketones, $\mathrm{x}$-Ac and $\mathrm{x}, \mathrm{y}^{\prime}$-diAc, as isolated after work-up, but also the $\mathrm{AlCl}_{3}$ complexes; the $1: 1 \mathrm{AlCl}_{3}$ complexes for the monoketones and the 1:1 and 1:2 complexes for the diketones.

Theoretical data obtained by DFT B3LYP 6-31 G(d,p) calculations for the mono- and diketones are summarized in Tables 3 and 4; the results for the $\mathrm{AlCl}_{3}$ complexes are included in Additional file 1: Scheme S1, Tables S1, S2 and S3.

The data in Table 3 show that the biphenyl dihedral angles, $\theta$, for 4-Ac and 5-Ac are close to that for unsubstituted $3,3^{\prime}$-dmbp. All fall in the range $37-39^{\circ}$, which is

Table 4 Total energies, Gibbs free energies (298 K), and structural properties for the acetyl substituted 4-acetyl-3,3'dimethylbiphenyls, 4,y'-diAc

\begin{tabular}{|c|c|c|c|c|c|c|}
\hline \multirow[t]{2}{*}{ Substituents } & \multirow{2}{*}{$\begin{array}{l}\text { Total energy } \\
\mathrm{E} \text { (a.u.) }\end{array}$} & \multirow[t]{2}{*}{$G_{298}$ (a.u.) } & \multirow{2}{*}{$\begin{array}{l}\mathrm{G}_{298} \text { relative to } 4,5^{\prime}- \\
\operatorname{diAc}\left(\mathrm{kJ} \mathrm{mol}^{-1}\right)\end{array}$} & \multirow{2}{*}{$\begin{array}{l}\theta^{\mathrm{a}} \\
\text { (degrees) }\end{array}$} & \multicolumn{2}{|c|}{$\varphi^{\mathrm{b}}$ (degrees) } \\
\hline & & & & & 4-Ac & $y^{\prime}-A c$ \\
\hline $4,2^{\prime}-\mathrm{di} A \mathrm{c}$ & -847.247523 & -846.984334 & 35.3 & 48.2 & 0.1 & 61.5 \\
\hline $4,4^{\prime}-\mathrm{diAc}$ & -847.256356 & -846.992372 & 14.2 & 36.5 & 1.0 & 1.0 \\
\hline $4,5^{\prime}-\mathrm{di} A \mathrm{c}$ & -847.259523 & -846.997775 & 0 & 36.7 & 0.7 & 0.4 \\
\hline 4,6'-diAc & -847.250427 & -846.988520 & 24.3 & 53.0 & 0.6 & 32.4 \\
\hline
\end{tabular}

Results from DFT B3LYP 6-31 G(d,p) calculations. 'Dihedral angle between the two benzene rings taken as the average of the C2-C1-C1'-C6' and C6-C1-C1'-C2 dihedral angles. ${ }^{b}$ Dihedral angle between the carbonyl group and the benzene ring to which it is attached taken as the $C_{A r}-C_{A r}-C=O$ dihedral angle. 


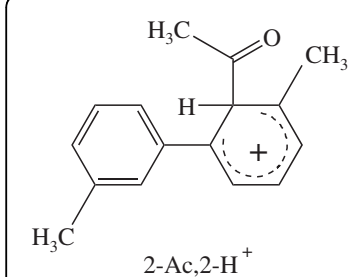

$2-\mathrm{Ac}, 2-\mathrm{H}^{+}$

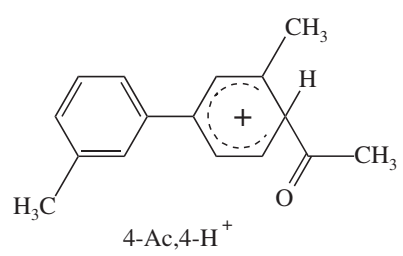

4-Ac, $4-\mathrm{H}^{+}$
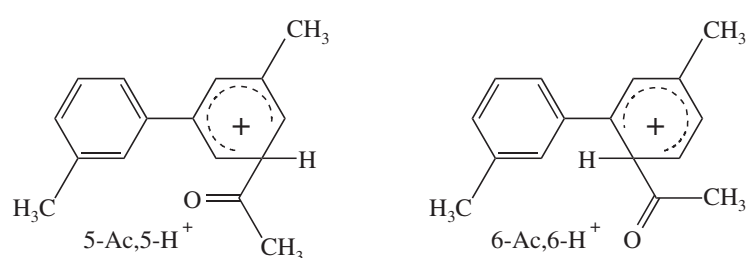

Scheme 2 The $\sigma$-complexes for monoacetylation.

within the range of values determined for $3,3^{\prime}$-dmbp by photoelectron [46-48] or NMR spectroscopy [49,50]. It is seen also that the $\mathrm{C}_{\mathrm{Ar}}-\mathrm{C}_{\mathrm{Ar}}-\mathrm{C}=\mathrm{O}$ dihedral angle, $\phi$, between the carbonyl group and the benzene ring to which it is attached is close to $0^{\circ}$ for 4-Ac and 5-Ac showing that the steric interactions between the 4-Ac group and the neighboring hydrogen and methyl, and between the 5-Ac group and the two neighboring hydrogens, are negligible. In contrast, the geometries for the two other isomers, 2-Ac and 6-Ac, are both affected by steric interactions between the acetyl group and the $2^{\prime}$ - and $6^{\prime}$-hydrogens in the neighboring ring. These interactions cause $\theta$ to increase from approximately $38^{\circ}$ to $49^{\circ}$ (2-Ac) and $54^{\circ}$ (6-Ac) and steric interactions also hinder co-planarity of the carbonyl group and the aromatic ring as reflected by $\phi$ values as high as $60.8^{\circ}$ (2-Ac) and $31.3^{\circ}$ (6-Ac). As a consequence of this both 2-Ac and 6-Ac suffer from diminished electronic conjugation resulting in values of $\mathrm{G}_{298}$ that are 33.7 and $22.5 \mathrm{~kJ} \mathrm{~mol}^{-1}$, respectively, higher than $\mathrm{G}_{298}$ for the lowest energy isomer, 5 -Ac. It is seen also that 5 -Ac is $12 \mathrm{~kJ} \mathrm{~mol}^{-1}$ more stable than 4-Ac, the only isomer isolated after workup. The stability of the four monoacetyl derivatives decreases in the order $5>4>6>2$ and thus, the isomer with an 1,3,5-arrangement of the three substituents (Ac, $\mathrm{Me}$ and $\mathrm{Ar}$ ) in the acetylated benzene ring is found to be the most stable reminiscent of the relative stability of trialkylbenzenes [51].

Complexation with $\mathrm{AlCl}_{3}$ has only a minor effect on the structure of the monoketones (Additional file 1: Table S1), but we do notice that $2-\mathrm{AcAlCl}_{3}$ and $4-\mathrm{AcAlCl}_{3}$ are both destabilized relative to the two other $\mathrm{AlCl}_{3}$ complexes presumably owing to steric interactions between the bulky $\mathrm{AlCl}_{3}$ group and the neighboring $3-\mathrm{CH}_{3}$ group. For 4-
$\mathrm{AcAlCl}_{3}$ these interactions also cause $\phi$ to increase from $\sim 0$ to $11.4^{\circ}$. However, the order of decreasing stability of the $\mathrm{AlCl}_{3}$ complexes remains the same as that for the uncomplexed ketones.

Comparison of the data in Table 3 for the monoketones with those in Table 4 for the diketones shows that the presence of the 4-Ac group has only little effect on the geometry, and the relative stability of the diketones is found to decrease in the same order as before, that is $4,5^{\prime}>4,4^{\prime}>4,6^{\prime}>4,2^{\prime}$. Similarly, by comparison of the data in Additional file 1: Table $\mathrm{S} 1$ for the $\mathrm{AlCl}_{3} \mathrm{com}$ plexes of the monoketones with those in Tables S2 and $\mathrm{S} 3$ for the $\mathrm{AlCl}_{3}$ complexes of the diketones we see no new effects on the structure and the relative stability caused by complexation of the diketones with $\mathrm{AlCl}_{3}$.

Thus, it is clear that the Friedel-Crafts mono- and diacetylation of 3,3'-dmbp with $\mathrm{AcCl}$ and $\mathrm{AlCl}_{3}$ under the Perrier conditions does not favor the formation of the most stable ketones or ketone $\mathrm{AlCl}_{3}$ complexes and thus appears, as expected, to be under kinetic control.

\section{The relative stability of the $\sigma$-complexes}

Let us now briefly examine the classical ionic mechanism for acetylation and test whether the distribution of the products is indeed reflected by the relative stability of the $\sigma$-complexes shown in Scheme 2 (for monosubstitution only) as one might expect for a kinetically controlled reaction. The relative stabilities of the four $\sigma-$ complexes leading to monoacetylation are summarized in Table 5 (the data for the corresponding $\mathrm{AlCl}_{3} \mathrm{com}$ plexes are included Additional file 1: Scheme S2 and Table S4). The order of decreasing stability is seen from Table 5 to be $4 \approx 6>2>5$ in agreement with the

Table 5 Total energies, Gibbs free energies (298 K), and structural properties for the $\sigma$-complexes, $x-A c, x-H^{+}$

\begin{tabular}{|c|c|c|c|c|}
\hline Substituent & Total energy $E$ (a.u.) & $\mathrm{G}_{298}$ (a.u.) & $\begin{array}{l}\mathrm{G}_{298} \text { relative to } 4- \\
\mathrm{Ac} 4-\mathrm{H}^{+}(\mathrm{kJ} \mathrm{mol}\end{array}$ & $\theta^{a}$ (degrees) \\
\hline $2-\mathrm{Ac}, 2-\mathrm{H}^{+}$ & -694.942784 & -694.702831 & 7.3 & 24.9 \\
\hline $4-\mathrm{Ac}, 4-\mathrm{H}^{+}$ & -694.945838 & -694.705627 & 0 & 23.3 \\
\hline $5-\mathrm{Ac}, 5-\mathrm{H}^{+}$ & -694.929221 & -694.692290 & 35.0 & 36.8 \\
\hline $6-\mathrm{Ac}, 6-\mathrm{H}^{+}$ & -694.944629 & -694.705485 & 0.4 & 32.3 \\
\hline
\end{tabular}

Results from DFT B3LYP 6-31 G(d,p) calculations. 'Dihedral angle between the two benzene rings taken as the average of the C2-C1-C1'-C6' and C6-C1-C1'-C2' dihedral angles. 
Table 6 Total energies, Gibbs free energies $(298 \mathrm{~K})$, and structural properties for the $\sigma$-complexes, 4-Ac, $\mathbf{y}^{\prime}-\mathrm{Ac}, \mathrm{y}^{\prime}-\mathrm{H}^{+}$

\begin{tabular}{|c|c|c|c|c|}
\hline Substituent & Total energy $E$ (a.u.) & $\mathrm{G}_{298}$ (a.u.) & 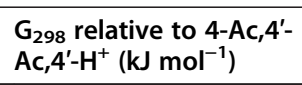 & $\theta^{a}$ (degrees) \\
\hline $4-\mathrm{Ac}, 2^{\prime}-\mathrm{Ac}, 2^{\prime}-\mathrm{H}^{+}$ & -847.582972 & -847.310553 & 6.6 & 31.8 \\
\hline $4-A c, 4^{\prime}-A c, 4^{\prime}-H^{+}$ & -847.585556 & -847.313061 & 0 & 23.9 \\
\hline $4-A c, 5^{\prime}-A c, 5^{\prime}-H^{+}$ & -847.571021 & -847.300305 & 33.5 & 36.5 \\
\hline $4-A c, \sigma^{\prime}-A c, 6^{\prime}-H^{+}$ & -847.584905 & -847.312773 & 0.8 & 32.3 \\
\hline
\end{tabular}

Results from DFT B3LYP 6-31 G(d,p) calculations. 'Dihedral angle between the two benzene rings taken as the average of the $\mathrm{C} 2^{2}-\mathrm{C} 1-\mathrm{C} 1^{\prime}-\mathrm{C} 6^{\prime}$ and $\mathrm{C} 6-\mathrm{C} 1-\mathrm{C} 1^{\prime}-\mathrm{C} 2^{\prime}$ dihedral angles.

observation that 5 -Ac is not formed in spite of the fact that this is the most stable isomer as already mentioned above, but it is noticed also that $\mathrm{G}_{298}$ for $4-\mathrm{Ac}, 4-\mathrm{H}^{+}$that leads to the only product formed is only $0.4 \mathrm{~kJ} \mathrm{~mol}^{-1}$ lower than $\mathrm{G}_{298}$ for $6-\mathrm{Ac}, 6-\mathrm{H}^{+}$. The same is true for the
$\mathrm{AlCl}_{3}$ complexes, $\mathrm{x}-\mathrm{AcAlCl}_{3}, \mathrm{x}-\mathrm{H}^{+}$(Additional file 1: Table S4). Thus, the theoretical data for the relative stability of the $\sigma$-complexes for monoacetylation would predict the formation of both 4-Ac and 6-Ac as major products. This is in contrast to the experimental

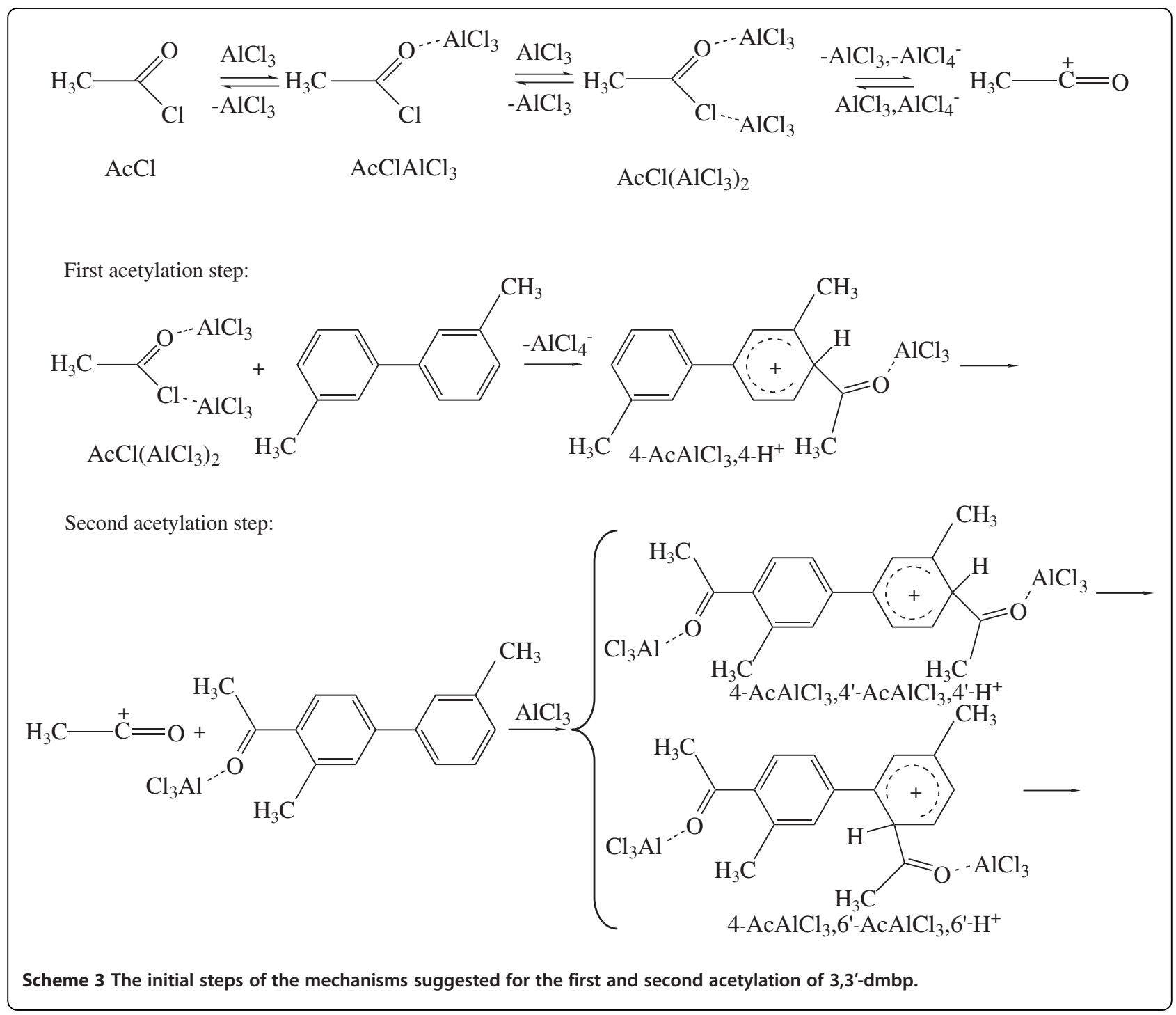


observation that 4-Ac is formed exclusively and therefore it appears that a feature of the reaction, so far not accounted for, causes the discrimination against the formation of 6-Ac. Here we wish to emphasize that the small energy differences found for 4-Ac,4- $\mathrm{H}^{+}$and 6$\mathrm{Ac}, 6-\mathrm{H}^{+}$, and for $4-\mathrm{AcAlCl}_{3}, 4-\mathrm{H}^{+}$and $6-\mathrm{AcAlCl}_{3}, 6-\mathrm{H}^{+}$, do not appear to be a computational artifact. More advanced computational strategies including the application of the larger $6-311+G(d, p)$ basis set or the inclusion of $\mathrm{AlCl}_{4}^{-}$ion pairs and PCM solvation result in energy differences that are still very small. Thus, the similarity of the energies of the two cations seems to be real. We will return to the implications of this result below.

The theoretical data for the four $\sigma$-complexes leading to diacetylation are summarized in Table 6 (the data for the corresponding $\mathrm{AlCl}_{3}$ complexes are included Additional file 1: Scheme S2, Tables S5 and S6).

Comparison of the data in Tables 5 and 6 shows that the presence of the 4-Ac group, as also intuitively expected, does not have a significant effect on the relative stability of the $\sigma$-complexes that decreases in the same order as for monoacetylation, that is $4,4^{\prime} \approx 4,6^{\prime}>4,2^{\prime}>4,5^{\prime}$. The same is true for the $\mathrm{AlCl}_{3}$ complexes, but we do notice (Additional file 1: Table S5) that the 1:1 complexes that involve the acetyl group resulting from the electrophilic attack are of significantly higher energies than those involving the 4-Ac group and therefore appear to be of only minor importance. Thus, in contrast to the monoacetylation the theoretical data for diacetylation are indeed in agreement with the assumption that the product distribution, that is the formation 4,4'-diAc and 4,6'-diAc in similar amounts, reflects the relative stability of the $\sigma$-complexes. In other words, the classical ionic mechanism may well be in operation for the diacetylation process.

The problem that remains is the effective discrimination against 6-Ac during monoacetylation. Here we should bring into mind that the composition of the $\mathrm{AcCl}-\mathrm{AlCl}_{3}$ mixtures, such as those used under the Perrier conditions, may contain not only the free acetyl cations, but also ionpairs involving this species as well as acetylating species resulting from the complexation between $\mathrm{AcCl}$ and $\mathrm{AlCl}_{3}$ and possibly even larger agglomerates, the actual distribution of these species of course being dependent on the solvent and the concentration ratio of $\mathrm{AcCl}$ and $\mathrm{AlCl}_{3}$. We find it likely that acetylation of the unsubstituted 3,3'-dmbp may involve such larger acetylation species reminiscent of the substitution mechanism [5] and that the discrimination against attack at the 6-position is caused by steric hindrance, whereas the deactivated 4-Ac derivative requires the smaller, more potent, and thus less discriminating, acetyl cation as in the ionic mechanism. This is illustrated in Scheme 3. We are presently engaged in more detailed experimental and theoretical studies of this problem.

\section{Experimental Materials}

4,4'-Diamino-3,3'-dimethylbiphenyl, 3-methylaniline, pentyl nitrite, acetyl chloride, anhydrous aluminium chloride, copper powder, potassium hydroxide, sodium hypochlorite (6\% available chlorine), silica gel and THF were from BDH and chloroform, dichloroethane, hydrochloric acid, benzene and petroleum ether were from Aldrich. Silica gel used for column chromatography was 230-400 mesh ASTM from Merck. All solvents used were of analytical purity from Fluka and were dried over anhydrous calcium chloride or anhydrous sodium sulfate prior to use in the acetylation reactions.

\section{Instrumentation}

IR spectra were measured as $\mathrm{KBr}$ discs or as thin films of Nujol on a Pye Unicam sp3-300 spectrophotometer. ${ }^{1} \mathrm{H}$ NMR spectra were recorded on a Varian FT-80 MHz and Bruker $100 \mathrm{MHz}$ for solutions in deuterated chloroform, using tetramethylsilane as an internal standard. GLC analyses were carried out with a stainless steel column $(2 \mathrm{~m} \times 2.2 \mathrm{~mm}$ i.d.) packed with SE-30 $(10 \%)$ on acid-washed Chromosorb W (80-100 mesh). Nitrogen $\left(15 \mathrm{lb} \mathrm{in}^{-2}\right)$ was used as carrier gas at $250^{\circ} \mathrm{C}$; a Pye Unicam 204 instrument fitted with flame ionization detector was used. Peak areas were measured by Pye Unicam DP 88 electronic integrator. Mass response towards the different compounds was determined and appropriate corrections were applied. Elemental analyses were carried out in Alfred Bernhard Mikroanalytisches Laboratorium, Germany. Mass spectra were obtained on a VG MassLab 12-250 GC mass spectrometer.

\section{General acetylation procedure}

The route for the synthesis of the ketones and carboxylic acids is depicted in Scheme 1.

The Friedel-Crafts acetylations were carried out in a three-necked round-bottomed flask placed in oil bath and fitted with a dropping funnel, a thermometer and a reflux condenser with a calcium chloride absorption trap. Equimolar quantities of the reactants in the dry solvent $(20 \mathrm{~mL})$ were brought together under the Perrier conditions, where the catalyst and acylating agent were allowed to react prior to addition of the substrate. A stoichiometric amount of 3,3'-dmbp in the same solvent $(20 \mathrm{~mL})$ was added drop wise over a period of $5 \mathrm{~min}$ to the stirred reaction mixture at the desired temperature. Stirring was continued at the same temperature for the total time shown in the Tables below. The mixture was then added to an excess of crushed ice and $3 \mathrm{M} \mathrm{HCl}$. The organic phase was separated and the water phase was washed with the organic solvent. The combined organic phases were then washed with water $(5 \times 50 \mathrm{~mL})$, dried with anhydrous sodium sulfate and finally the 
solvent was removed at reduced pressure using a rotary evaporator. When nitromethane was used as the solvent, the organic layer was washed with $(2 \times 100 \mathrm{~mL})$ of $3 \mathrm{M}$ $\mathrm{NaOH}$ instead of water. The viscous residue was dissolved in benzene and passed through a short column of silica gel to remove any polymeric materials. The reaction mixtures were examined for the content of ketones by GLC analysis. The symmetry of 3,3'-dmbp molecule limits the number of isomeric monosubstituted derivatives to four at 2-, 4-, 5and 6- position and the identity of each component was established by comparison of the retention time with that of authentic samples and by oxidizing the ketones to the corresponding carboxylic acids. The overall yield of products is presented in Tables 1 and 2 above. The monoand diketones synthesized were identified by their ${ }^{1} \mathrm{H}$ NMR, IR, mass spectra and by elemental analysis.

\section{Preparations}

\section{Preparation of 3,3'-dimethylbiphenyl}

Two different methods, A and B below, for the preparation of 3,3'-dmbp was followed, both of which gave identical products. (A): 3,3'-dmbp was prepared by deamination of 4,4'-diamino-3,3'-dmbp following a published procedure [52]. 4,4'-diamino-3,3'-dmbp (4.24 g, $0.02 \mathrm{~mol})$ in THF $(50 \mathrm{~mL})$ was added drop-wise within $2 \mathrm{~h}$ to a boiling solution of pentyl nitrite $(23.4 \mathrm{~g}, 0.2 \mathrm{~mol})$ in THF $(30 \mathrm{~mL})$. The obtained mixture was refluxed for $6 \mathrm{~h}$. Distillation of the solvent resulted in a viscous dark brown liquid. The viscous liquid was extracted with chloroform then the solvent was evaporated. The remaining material was distilled under vacuum. An oily colorless liquid of 3,3'-dmbp was obtained (3.1 g, 84\%). (B): Ullmann synthesis starting from 3-methylaniline. 3-iodotoluene was prepared from 3-methylaniline using the general method [36] where a colorless liquid was obtained; bp. $214^{\circ} \mathrm{C}$ (lit. [53] $213^{\circ} \mathrm{C}$ ). A mixture of 3iodotoluene (42 g, $0.2 \mathrm{~mol})$ and copper powder (24.4 g, $0.4 \mathrm{~mol}$ ) was refluxed for $72 \mathrm{~h}$. After cooling the mixture was dissolved in chloroform and filtered off. On evaporation of the solvent a brown liquid was obtained distilled under vacuum which gave a colorless liquid of 3,3'-dmbp (21 g, 60\%); b.p. $146^{\circ} \mathrm{C} / 17 \mathrm{mmHg}$. (lit. [54] $135^{\circ} \mathrm{C} / 3 \mathrm{mmHg}$ ) (Found $\mathrm{C}, 92.16 ; \mathrm{H}, 7.71 \% ; \mathrm{C}_{14} \mathrm{H}_{14}$ requires $\mathrm{C}$, 92.26; $\mathrm{H}$, 7.74\%). $\delta\left(\mathrm{CDCl}_{3}\right) 2.43\left(6 \mathrm{H}, \mathrm{s}, 3-\mathrm{CH}_{3}\right.$ and $\left.3^{\prime}-\mathrm{CH}_{3}\right), 7.17-$ $7.31(6 \mathrm{H}, \mathrm{m}$, aromatic $\mathrm{H}), 7.53\left(\mathrm{~d}, \mathrm{~J}=7.8 \mathrm{~Hz}, 2 \mathrm{H}, \mathrm{H}-6,6^{\prime}\right)$.

\section{4-Acetyl-3,3'-dimethylbiphenyl}

To a stirred solution of acetyl chloride $(0.392 \mathrm{~g} ; 0.005 \mathrm{~mol})$ and aluminium chloride ( $0.666 \mathrm{~g} ; 0.005 \mathrm{~mol})$ in 1,2-dichloroethane $(20 \mathrm{~mL}), 3,3^{\prime}$-dmbp $(0.91 \mathrm{~g} ; 0.005 \mathrm{~mol})$ in the same solvent $(20 \mathrm{~mL})$ was added and the mixture was stirred at room temperature for $1 \mathrm{~h}$ and then refluxed for $22 \mathrm{~h}$. The mixture was then added to an excess of crushed ice and $3 \mathrm{M} \mathrm{HCl}$. The organic phase was separated, the extract was added to the washing (solvent) of the acid layer and the combined extracts were washed with water $(5 \times 50 \mathrm{~mL})$ and the solvent removed by rotary evaporator. The dark brown oil obtained was dissolved in benzene, chromatographed over silica gel/petroleum ether first to get rid of the remaining starting hydrocarbon, and then the ketone was obtained by using benzene as an eluent. Evaporation of benzene affords pure 4-acetyl-3,3'-dmbp $(0.98 \mathrm{~g} ; 87.1 \%)$ as a yellow oil: Found $\mathrm{C}, 85.54 ; \mathrm{H}$, 7.19\%; $\mathrm{C}_{16} \mathrm{H}_{16} \mathrm{O}$ requires $\left.\mathrm{C}, 85.68 ; \mathrm{H}, 7.19 \%\right) . v_{\max }$ (neat) $1680(\mathrm{C}=\mathrm{O}) \mathrm{cm}^{-1} ; \delta\left(\mathrm{CDCl}_{3}\right) 2.43\left(\mathrm{~s}, 3 \mathrm{H}, 3^{\prime}\right.$ $\left.\mathrm{CH}_{3}\right), 2.58\left(\mathrm{~s}, 6 \mathrm{H}, 3-\mathrm{CH}_{3}\right.$ and $\left.4-\mathrm{CH}_{3} \mathrm{CO}\right), 7.17-7.53$ $(6 \mathrm{H}, \mathrm{m}$, aromatic $\mathrm{H}), 7.78\left(\mathrm{~d}, \mathrm{~J}_{5,6}=9 \mathrm{~Hz}, 1 \mathrm{H}, \mathrm{H}-\right.$ $\left.6^{\prime}\right) . \mathrm{m} / \mathrm{z} 224[\mathrm{M}]^{+}, 209$ [base peak, M-CH$]^{+}, 181[\mathrm{M}-$ $\left.\mathrm{COCH}_{3}\right]^{+}, 151\left[\mathrm{M}-\left(2 \mathrm{CH}_{3}+\mathrm{COCH}_{3}\right)\right]^{+}, 89\left[\mathrm{PhCH}_{3}\right]^{+}, 76$ $\left[\mathrm{C}_{6} \mathrm{H}_{4}\right]^{+}, 43\left[\mathrm{COCH}_{3}\right]^{+}$.

\section{3,3'-Dimethylbiphenyl-4-carboxylic acid}

A mixture of 4-acetyl-3,3'-dmbp (2.1 g; $0.009 \mathrm{~mol})$, potassium hydroxide $(1.5 \mathrm{~g})$ and sodium hypochlorite $(150 \mathrm{~mL})$ was heated for $3 \mathrm{~h}$. Additional quantities of hypochlorite solution $(45 \mathrm{~mL})$ were added to the mixture after 1 and $2 \mathrm{~h}$. After cooling, the solution was acidified with $50 \% \mathrm{HCl}$ and the precipitate was extracted with ether $(4 \times 25 \mathrm{~mL})$, washed with water then with dilute potassium hydroxide. The basic layer was separated, acidified with dilute $\mathrm{HCl}$ and a precipitate was formed which was extracted with ether. The acid was obtained after ether evaporation as yellow crystals (1.13 g; 53\%), mp $168-170^{\circ} \mathrm{C} . v_{\max }(\mathrm{KBr}) 1683$ $(\mathrm{C}=\mathrm{O})$ and $3040(\mathrm{OH}) \mathrm{cm}^{-1} \delta\left(\mathrm{CDCl}_{3}\right) 2.45\left(\mathrm{~s}, 3 \mathrm{H}, 3^{\prime}-\right.$ $\left.\mathrm{CH}_{3}\right), 2.73\left(\mathrm{~s}, 3 \mathrm{H}, 3-\mathrm{CH}_{3}\right), 7.25-7.47(\mathrm{~m}, 6 \mathrm{H}$, aromatic $\mathrm{H})$, $8.14\left(\mathrm{~d}, \mathrm{~J}_{5^{\prime}, 6^{\prime}}{ }^{\prime}=8.5 \mathrm{~Hz}, 1 \mathrm{H}, \mathrm{H}-6^{\prime}\right), 11.69(\mathrm{~s}, 1 \mathrm{H}, 4-\mathrm{COOH}$ exchangeable with $\mathrm{D}_{2} \mathrm{O}$ ). (Found $\mathrm{C}, 79.62 ; \mathrm{H}, 6.24 \%$; $\mathrm{C}_{15} \mathrm{H}_{14} \mathrm{O}_{2}$ requires $\mathrm{C}, 79.65 ; \mathrm{H}, 6.19 \%$ ).

\section{4,4'- and 4,6'-diacetyl-3,3'-dimethylbiphenyl}

To a stirred solution of acetyl chloride ( $3.136 \mathrm{~g} ; 0.04 \mathrm{~mol}$ ) and aluminium chloride anhydrous $(5.323 \mathrm{~g} ; 0.04 \mathrm{~mol})$ in 1,2-dichloroethane (40 mL), 3,3'-dmbp (1.82 g; $0.01 \mathrm{~mol})$ in the same solvent $(40 \mathrm{~mL})$ was added drop wise over 5 minutes. The mixture was stirred at room temperature for $1 \mathrm{~h}$ then gently refluxed for $22 \mathrm{~h}$. At the end of the reaction time, the resulting mixture was cooled and added to a mixture of conc. $\mathrm{HCl}$ and ice. The dark brown viscous oil obtained was chromatographed over silica gel/benzene. The yellow oil obtained on evaporation of benzene. A yellow solid $\left(0.86\right.$ g, m.p. $\left.129-131^{\circ} \mathrm{C}\right)$ was obtained on adding a little of benzene. Recrystallization of the yellow solid using ether gave 4,4'-diacetyl-3,3' -dmbp as yellow needles (0.79 g, 29\%) m.p. $131-3^{\circ} \mathrm{C}$. (lit. [55] $136^{\circ} \mathrm{C}$ ). Found C, 81.11; $\mathrm{H}, 6.74 \% ; \mathrm{C}_{18} \mathrm{H}_{18} \mathrm{O}_{2}$ requires $\left.\mathrm{C}, 81.17 ; \mathrm{H}, 6.81 \%\right)$. $v_{\max }(\mathrm{KBr}) 1684(\mathrm{C}=\mathrm{O}) \mathrm{cm}^{-1} \delta\left(\mathrm{CDCl}_{3}\right) 2.62(\mathrm{~s}, 12 \mathrm{H}, 3-$ $\left.\mathrm{CH}_{3}, 3^{\prime}-\mathrm{CH}_{3}, 4-\mathrm{COCH}_{3}, 4^{\prime}-\mathrm{COCH}_{3}\right), 7.29-7.61(\mathrm{~m}, 4 \mathrm{H}$, aromatic $\mathrm{H}), 7.83\left(\mathrm{~d}, \mathrm{~J}_{5,6}\right.$ and $\left.\mathrm{J}_{5}{ }^{\prime}, 6^{\prime}=8.9 \mathrm{~Hz}, 2 \mathrm{H}, \mathrm{H}-5,5^{\prime}\right)$. 
The mother liquor was subjected to column chromatography, which gave rise to, first, the 4,4'-diacetyl-3,3' -dmbp and, second, 4,6' -diacetyl-3,3' -dmbp (1.13 g, 42.5\%). (found C, 81.03; $\mathrm{H}, 6.71 \% ; \mathrm{C}_{18} \mathrm{H}_{18} \mathrm{O}_{2}$ requires $\mathrm{C}$, 81.17; $\mathrm{H}, 6.81 \%$ ). $v_{\max }(\mathrm{KBr}) 1685(\mathrm{C}=\mathrm{O}) \mathrm{cm}^{-1} \delta(\mathrm{CDCl} 3) 2.00\left(\mathrm{~s}, 3 \mathrm{H}, 3^{\prime}-\right.$ $\mathrm{CH}_{3}$ ), 2.39 (s, $\left.3 \mathrm{H}, 3-\mathrm{CH}_{3}\right), 2.56$ (s, $6 \mathrm{H}, 4-\mathrm{COCH}_{3}, 6{ }^{\prime}-$ $\left.\mathrm{COCH}_{3}\right), 7.14-7.29(\mathrm{~m}, 4 \mathrm{H}$, aromatic $\mathrm{H}), 7.52(\mathrm{~d}$, $\left.\mathrm{J}_{4,5^{\prime}}{ }^{\prime}=9 \mathrm{~Hz}, 1 \mathrm{H}, \mathrm{H}-5^{\prime}\right), 7.71$ (d, J5,6 $\left.=9 \mathrm{~Hz}, 1 \mathrm{H}, \mathrm{H}-5\right) . \mathrm{m} / \mathrm{z}$ $266[\mathrm{M}]^{+}, 251$ [base peak, M-CH$]^{+}, 209\left[\mathrm{M}-\left(\mathrm{CH}_{3}+\right.\right.$ $\left.\mathrm{COCH}_{3}\right]^{+}, 164\left[\mathrm{M}-\left(2 \mathrm{CH}_{3}+\mathrm{COCH}_{3}\right)\right]^{+}, 151\left[\mathrm{M}-\left(2 \mathrm{CH}_{3}+2\right.\right.$ $\left.\mathrm{COCH}_{3}\right]^{+}, 118\left[\mathrm{PhCOCH}_{3}\right]^{+}, 89\left[\mathrm{PhCH}_{3}\right]^{+}, 76\left[\mathrm{C}_{6} \mathrm{H}_{4}\right]^{+}, 43$ $\left[\mathrm{COCH}_{3}\right]^{+}$.

\section{3,3'-Dimethylbiphenyl-4,4'-dicarboxylic acid}

A mixture of 4,4' -diacetyl-3,3'-dmbp (0.2 g; $0.007 \mathrm{~mol})$, potassium hydroxide $(1.0 \mathrm{~g})$ and sodium hypochlorite $(100 \mathrm{~mL})$ was heated for $4 \mathrm{~h}$. Additional quantities of hypochlorite solution $(30 \mathrm{~mL})$ were added to the mixture after 1, 2 and $3 \mathrm{~h}$. After cooling, the solution was acidified with $50 \% \mathrm{HCl}$ and the precipitate was extracted with ether $(4 \times 25 \mathrm{~mL})$, washed with water then with dilute potassium hydroxide. The basic layer was separated, acidified with dilute $\mathrm{HCl}$ and a white precipitate was formed and filtered. The solid acid obtained was recrystallized from benzene which gave a white crystals of 3,3'-dmbp-4,4'-dicarboxylic acid. (0.09 g; 44.3\%), mp $190^{\circ} \mathrm{C}(\mathrm{d}) . v_{\max }(\mathrm{KBr}) 1687(\mathrm{C}=\mathrm{O})$ and $3050(\mathrm{OH}) \mathrm{cm}^{-1}$ (found $\mathrm{C}$, 71.56; $\mathrm{H}, 5.28 \% ; \mathrm{C}_{16} \mathrm{H}_{14} \mathrm{O}_{4}$ requires $\mathrm{C}$, 71.11; $\mathrm{H}, 5.19 \%) . \delta\left(\mathrm{CDCl}_{3}\right) 2.67\left(\mathrm{~s}, 6 \mathrm{H}, 3-\mathrm{CH}_{3}\right.$ and $\left.3^{\prime}-\mathrm{CH}_{3}\right)$, 7.25-7.67 (m, 4 H, aromatic H), $8.04\left(\mathrm{~d}, \mathrm{~J}_{5,6}=8.5 \mathrm{~Hz}\right.$, $2 \mathrm{H}, \mathrm{H}-5$ and $\mathrm{H}-5^{\prime}$ ), 11.83 (s, $2 \mathrm{H}, 4$ - and 4' $-\mathrm{COOH}$ exchangeable with $\mathrm{D}_{2} \mathrm{O}$ )

\section{3,3'-Dimethylbiphenyl-4,6'-dicarboxylic acid}

A mixture of 4,6'-diacetyl-3,3'-dmbp (0.2 g; $0.007 \mathrm{~mol})$, potassium hydroxide $(1.0 \mathrm{~g})$ and sodium hypochlorite $(100 \mathrm{~mL})$ was heated for $5 \mathrm{~h}$. Additional quantities of hypochlorite solution $(30 \mathrm{~mL})$ were added to the mixture after 1, 2, 3 and $4 \mathrm{~h}$. After cooling, the solution was acidified with $50 \% \mathrm{HCl}$ and the precipitate was extracted with ether $(4 \times 25 \mathrm{~mL})$, washed with water then with dilute potassium hydroxide. The basic layer was separated, acidified with dilute $\mathrm{HCl}$ and a white precipitate was formed and filtered. The white solid obtained was recrystallized from ether/benzene which gave a white crystals of 3,3'-dmbp-4,6' -dicarboxylic acid. (0.076 g; $37.3 \%), \mathrm{mp}>340^{\circ} \mathrm{C}(\mathrm{d}) . v_{\max }(\mathrm{KBr}) 1690(\mathrm{C}=\mathrm{O})$ and $3050(\mathrm{OH}) \mathrm{cm}^{-1}$. Found $\mathrm{C}, 70.96 ; \mathrm{H}, 5.30 \% ; \mathrm{C}_{16} \mathrm{H}_{14} \mathrm{O}_{4}$ requires $\mathrm{C}, 71.11 ; \mathrm{H}, 5.19 \%) . \delta\left(\mathrm{CDCl}_{3}\right) 2.44\left(\mathrm{~s}, 3 \mathrm{H}, 3^{\prime}\right.$ $\left.\mathrm{CH}_{3}\right), 2.62\left(\mathrm{~s}, 3 \mathrm{H}, 3-\mathrm{CH}_{3}\right), 7.15-7.70(\mathrm{~m}, 5 \mathrm{H}$, aromatic H), $8.04\left(\mathrm{~d}, \mathrm{~J}_{5,6}=8.5 \mathrm{~Hz}, 1 \mathrm{H}, \mathrm{H}-5\right), 11.89$ (s, $2 \mathrm{H}, 4$ - and $6^{\prime}-\mathrm{COOH}$ exchangeable with $\mathrm{D}_{2} \mathrm{O}$ ).

\section{DFT calculations}

All calculations were carried out using the Gaussian 03 package [x86-Linux-G03RevB.05] of programs [56] installed on a PC cluster or the equivalent G03W suite of programs [version 6.1] installed on standard personal computers. The structure optimizations included the default or the gdiis procedures; geometrical constraints were not imposed. Thermochemical data at $\mathrm{T}=298 \mathrm{~K}$ were obtained by frequency calculations. The conformational space for the compounds investigated is large and a number of local energy minima were detected. The conformational analysis in this study included the effects (i) the syn/anti orientation of the two methyl-substituted rings, (ii) the orientation of the carbonyl group relative to the plane of the aromatic ring to which it is attached and (iii) the orientation of the carbonyl group in the $\sigma$-complexes. Data are given only for the conformers that we have found to be of lowest energy. With respect to the orientation of the acetyl group relative to a neighboring methyl substituent we find that the conformation having the carbonyl oxygen atom pointing towards the methyl group is preferred in agreement with the results obtained by others [57].

\section{Conclusions}

Friedel-Crafts acetylation of $3,3^{\prime}$-dmbp by the Perrier addition procedure in which a solution of the substrate was added to a stirred solution of the preformed complex of acetyl chloride and aluminium chloride has been investigated in detail. At $25,45^{\circ} \mathrm{C}$ and higher temperature (reflux conditions) with stoichiometric amounts of reagents, acetylations give 4-acetyl-3,3'-dmbp entirely with almost quantitative yield obtained in boiling 1,2-dichloroethane. In 1,2-dichloroethane at reflux conditions with a hydrocarbon:acetyl chloride:aluminium chloride molar ratio of 1:4:4 or 1:6:6 acetylation affords $4,4^{\prime}$ - and 4,6' -diacetyl$3,3^{\prime}$-dmbp as the sole products. The mono- and diketones were subsequently converted to the corresponding 3,3'dmbp dicarboxylic acids by hypochlorite oxidation. Two of the compounds, 4,6'-diacetyl-3,3'-dmbp and the dicarboxylic acid derived from this species are reported for the first time. The relative stability of the possible acetylation products as evaluated by DFT B3LYP 6-31 G(d,p) calculations indicates that the acetylations do not favor the formation of the most stable products and are under kinetic control.

\section{Additional file}

Additional file 1: Scheme S1. Illustrations of the $\mathrm{AlCl}_{3}$ complexes of the ketones. Table S1. Total energies, Gibbs free energies (298 K) and structural properties for the $\mathrm{AlCl}_{3}$ complexes, $\mathrm{x}-\mathrm{AcAlCl}_{3}$, of the monoacetyl isomers. Table S2. Total energies, Gibbs free energies at $(298 \mathrm{~K})$ and structural properties for the $1: 1 \mathrm{AlCl}_{3}$ complexes, 4-AcAlCl $3, \mathrm{Y}$ '-Ac and 4-Ac,y'-AcAlCl 3 , of the acetyl substituted 4-acetyl-3,3'-

dimethylbiphenyls. Table S3. Total energies, Gibbs free energies at 
$(298 \mathrm{~K})$ and structural properties for the $1: 2 \mathrm{AlCl}_{3}$ complexes, 4,y '-diAcAlCl , of the four acetyl substituted 4-acetyl-3,3'-dimethylbiphenyls. Scheme S2. Illustrations of the $\mathrm{AlCl}_{3}$ complexed $\sigma$-complexes. Table S4.

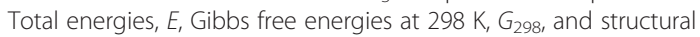
properties for the $\mathrm{AlCl}_{3}$ complexed $\sigma$-complexes, $\mathrm{x}-\mathrm{AcAlCl}_{3}, \mathrm{x}-\mathrm{H}^{+}$. Table S5. Total energies, E, Gibbs free energies at 298 K, G $G_{298}$, and structural properties for the 1:1 $\mathrm{AlCl}_{3}$ complexed $\sigma$-complexes, 4-AcAlCl $3, y^{\prime}-\mathrm{Ac}_{1} \mathrm{y}^{\prime}-\mathrm{H}^{+}$and 4-Ac,y '-AcAlCl ${ }_{3} y^{\prime}-H^{+}$. Table S6. Total energies, E, Gibbs free energies at $298 \mathrm{~K}, \mathrm{G}_{298}$ and structural properties for the 1:2 $\mathrm{AlCl}_{3}$ complexed $\sigma$-complexes, 4-AcAlCl $3, \mathrm{Y}$ '-AcAlCl $3, y^{\prime}-\mathrm{H}^{+}$.

\section{Competing interests}

The authors declare that they have no competing interests.

\section{Authors' contributions}

ST contributed to the findings and experimental part of the manuscript. FK contributed in the characterization of the compounds and contributed to the findings and experimental part of the manuscript. HA carried out the experimental work. OH carried out the computational work and contributed to the findings part the manuscript. All authors read and approved the final manuscript.

\section{Acknowledgements}

Prof. Stephan P. Sauer is gratefully acknowledged for giving us access to the computer cluster at which most of the DFT calculations were carried out. University of the Western Cape is gratefully acknowledged for the articleprocessing charge.

\section{Author details}

'Department of Chemistry, University of the Western Cape, Private Bag X17, Bellville, 7535, South Africa. ${ }^{2}$ CISMI, Department of Science, Systems and Models, Roskilde University, Universitetsvej 1, P.O. Box 260, Roskilde, DK-4000, Denmark. ${ }^{3}$ Department of Chemistry, University of Copenhagen, Universitetsparken 5, Copenhagen Ø, DK-2100, Denmark.

\section{Received: 25 February 2012 Accepted: 8 May 2012}

Published: 8 June 2012

\section{References}

1. Gore PH: Aromatic ketone synthesis. In Friedel-Crafts and related reactions. Edited by Olah GA. New York: Interscience Publ; 1964:1-381.

2. Olah GA: Friedel-Crafts Chemistry. New York: Wiley Interscience; 1973.

3. Olah GA, Reddy VP, Prakash GKS: Kirk-Othmer Encyclopedia of Chemical Technology. Volume 12. 5th edition. Hoboken: Wiley; 2005

4. Heaney H: The Bimolecular Aromatic Friedel-Crafts Reaction. In Comprehensive Organic Synthesis. Edited by Trost BM, Fleming I. Oxford: Pergamon Press; 1991:733-752.

5. Kurti L, Czako B: Strategic Applications of Named Reactions in Organic Synthesis. Burtington, MA: Elsevier Academic Press; 2005.

6. Effenberger $\mathrm{F}$, Maier AH: Changing the ortho/para ratio in aromatic acylation reactions by changing reaction conditions: a mechanistic explanation from kinetic measurements. J Am Chem Soc 2001, 123:3429-3433.

7. Csihony S, Mehdi H, Homonnay Z, Vértes A, Farkas O, Horváth IT: In situ spectroscopic studies related to the mechanism of the Friedel-Crafts acetylation of benzene in ionic liquids using $\mathrm{AlCl}_{3}$ and $\mathrm{FeCl}_{3}$.J Chem SoC Dalton Trans 2002, 680-685.

8. Davlieva MG, Lindeman SV, Neretin IS, Kochi JK: Isolation, X-ray structures, and electronic spectra of reactive intermediates in Friedel-Crafts acylations. J Org Chem 2005, 70:4013-4021.

9. Meneses L, Fuentealba P, Contreras R: Relationship between the electrophilicity of substituting agents and substrate selectivity in FriedelCrafts reactions. Tetrahedron 2005, 61:831-836.

10. Sartori G, Maggi R: Use of solid catalysts in Friedel-Crafts acylation reactions. Chem Rev 2006, 106:1077-1104.

11. Titinchi SJJ, Kamounah FS, Abbo HS: Preparation of mono- and diacetyl 4,4'-dimethylbiphenyl and their corresponding carboxylic acids: Reactivity, selectivity and isomer distribution studies via Lewis acid catalyzed Friedel-Crafts acetylation/oxidation. J Mol Catal A 2007, 273:169-176.
12. Levy L, Pogodin S, Cohen S, Agranat I: Reversible friedel-crafts acylations of phenanthrene: Rearrangements of acetylphenanthrenes. Lett Org Chem 2007, 4:314-318

13. Titinchi SJJ, Kamounah FS, Abbo HS, Hammerich O: The synthesis of mono-and diacetyl-9 H-fluorenes. Reactivity and selectivity in the Lewis acid catalyzed FriedelCrafts acetylation of $9 \mathrm{H}$-fluorene. ARKIVOC 2008, 13:91-105.

14. Mala'bi T, Pogodin S, Agranat I: Reversible Friedel-Crafts acylations of anthracene: Rearrangements of acetylanthracenes. Lett Org Chem 2009, 6:237-241

15. Yamabe S, Yamazaki S: A remarkable difference in the deprotonation steps of the Friedel-Crafts acylation and alkylation reactions. J Phys Org Chem 2009, 22:1094-1103.

16. Sartori G, Maggi R: Advances in Friedel-Crafts Acylation Reactions: Catalytic and Green Processes. Boca Raton: CRC Press; 2010.

17. Olah GA, Kobayashi S: Aromatic substitution. XXIX. Friedel-Crafts acylation of benzene and toluene with substituted acyl halides. Effect of substituents on substrate and positional selectivity. J Am Chem Soc 1971, 93:6964-6967.

18. Andreou AD, Bulbulian RV, Gore PH: Friedel-Crafts acetylation of durene, isodurene and prehnitene. Tetrahedron 1980, 36:2101-2104.

19. Tan LK, Brownstein S: Equilibria and reactions in the systems aluminum chloride-acetyl chloride-aromatic hydrocarbon in sulfur dioxide as solvent. J Org Chem 1983, 48:302-306.

20. Brown HC, Marino G: Rate data and isomer distributions in aluminum chloride-catalyzed acetylation and benzoylation of biphenyl and fluorene in ethylene dichloride. J Am Chem Soc 1962, 84:1236-1238.

21. Andreou AD, Bulbulian RV, Gore PH, Kamounah FS, Miri AY, Waters DN: The Friedel-Crafts acetylation of naphthalene. Evidence for concurrent secondand third-order reactions. J Chem Soc Perkin Trans 1981, 2:376-378.

22. Gore PH: The Friedel-Crafts acetylation of naphthalene. Z Phys Chem 1988, 159:123-128.

23. Dowdy D, Gore PH, Waters DN: The Friedel-Crafts acetylation of naphthalene in 1,2-dichloroethane solution. Kinetics and mechanism. $J$ Chem Soc Perkin Trans 1991, 2:1149-1159.

24. Gore PH, Thadani CK: Formation of mono- and diketones in the FriedelCrafts acetylation of anthracene. J Chem Soc C: Org 1966, 1729-1733.

25. Perin F, Croisy-Delcey M, Jacquignon P: Friedel-Crafts polycyclic aromatic hydrocarbon acylation reactions. IX. Acetylation of anthracene and its meso-methyl homologs. Can J Chem 1976, 54:1777-1788.

26. Girdler RB, Gore PH, Thadani CK: The Friedel-Crafts acetylation of phenanthrene. J Chem Soc C: Org 1967, 2619-2624.

27. Minabe M, Takeshige S, Soeda Y, Kimura T, Tsubota M: Electrophilic substitution of monosubstituted pyrenes. Bull Chem Soc Jpn 1994, 67:172-179.

28. Gore PH, Kamounah FS, Miri AY: Friedel-Crafts acetylations of two benzophenanthrenes. A study of relative rates of substitution of naphthalene, phenanthrene, chrysene, and triphenylene. J Chem Res (Synopses) 1980, 40:0530-0548.

29. Al-Ka'bi J, Gore PH, Moonga B, Al-Shiebani IS, Shibaldain NL, Kamounah FS: The Friedel-Crafts acylation of 1-methoxy-3,5-dimethylbenzene and the kinetics of protiodeacylation of the ketones thus obtained. J Chem Res (Synopses) 1986, 246-247.

30. Kamounah FS, Titinchi SJJ: 1 H-NMR study of some new acetyl dimethylbiphenyls: unambiguous signal assignment for the methyl groups. Spectroscopy 1997, 13:125-129.

31. Tobolsky AV, Samulski EJ: Solid 'liquid-crystalline' films of synthetic polypeptides. New state of matter. Adv Chem Phys 1971, 21:529-535.

32. Shiotani A, Washio K: Preparation of polyamides containing para-linked dimethylbiphenylene moieties. J Appl Polym Sci 1998, 68:847-853.

33. Kim J-H, Kimura M, Higashi F: Thermotropic copolyamides from triethylene glycol bis(4-carboxyphenyl) ether and o-tolidine modified by kinking monomers. J Polym Sci A Polym Chem 1999, 37:363-368.

34. Kettunen M, Vedder C, Brintzinger H-H, Mutikainen I, Leskela M, Repo T: Alternative coordination modes in palladium(II)-diimino-bispyridine complexes with an axially chiral biphenyl backbone. Eur J Inorg Chem 2005, 1081-1089.

35. Cook JW: Polycyclic aromatic hydrocarbons. IV. Condensed derivatives of 1,2-benzanthracene. J Chem Soc 1931, 499-507.

36. Dovgosheya MI, Krasovitskii BM: Some biphenyl derivatives as vinyl monomers. Zhur Org Khim 1966, 2:1288-1291.

37. Kotlyarevskii IL, Shvartsberg MS, Volgina GI, Vasilevskii SF: Synthesis of acetylene derivatives of diphenyl oxide and metabitolyl. IzV Akad Nauk SSSR Ser Khim 1965, 1704-1706. 
38. de la Mare PBD, Hall DM, Harris MM, Hassan M, Johnson EA, Klassen NV: The kinetics and mechanisms of aromatic halogen substitution. XIV. Rates and products of chlorination of methyl-substituted biphenyls in acetic acid. J Chem Soc 1962, 3784-3796.

39. Wirth $\mathrm{HO}$, Königstein $\mathrm{O}$, Kern W: lodination of aromatic compounds with iodine and iodic acid. Justus Liebigs Ann Chem 1960, 634:84-104.

40. Kortekaas TA, Cerfontain H: Aromatic sulfonation. Part 66. Sulfonation of some biphenyl derivatives. J Chem Soc Perkin Trans II:Phys Org Chem 1979, 224-227. doi:10.1039/P2979000022.

41. Clark JH, Miller JM: Hydrogen bonding in organic synthesis. Part 6. Intermolecular self-condensation of some enolisable ketones in the presence of fluoride. J Chem Soc Perkin Trans1:Org Bio-Org Chem 1977, 2063-2069. doi:10.1039/P19770002063.

42. Kamounah FS, Al-Sheibani I, Shibaldain NL, Salman SR: Proton magnetic resonance studies of substituted 3,5-dimethylbenzenes: influence of substituents on the methyl proton chemical shifts. Magn Reson Chem 1985, 23:521-523.

43. Jackman LM, Sternhell S: Applications of Nuclear Magnetic Resonance Spectroscopy in Organic Chemistry. 2nd edition. Oxford: Pergamon Press; 1969:546.

44. Fiedler $P$, Exner $\mathrm{O}$ : Conformation of aromatic carbonyl derivatives: an infrared study. Collect Czech Chem Commun 2004, 69:797-810.

45. Tan LK, Brownstein S: Initial products in Friedel-Crafts reactions. J Org Chem 1983, 48:3389-3393.

46. Maier JP, Turner DW: Steric inhibition of resonance studied by molecular photoelectron spectroscopy. 1. Biphenyls. Faraday Disc Chem Soc 1972, 54:149-167.

47. Modelli A, Distefano G, Jones D: Application of electron transmission spectroscopy to conformational studies: electron affinities of methylsubstituted biphenyls. Chem Phys 1983, 82:489-492.

48. Dynes JJ, Baudais FL, Boyd RK: Inter-ring dihedral angles in polychlorinated biphenyls from photoelectron spectroscopy. Can J Chem 1985, 63:1292-1299.

49. Roberts RMG: Conformational analysis of biphenyls using carbon-13 NMR spectroscopy. Magn Res Chem 1985, 23:52-54.

50. Bates RB, Camou FA, Kane W, Mishra PK, Suvannachut K, White JJ: Preparations and reactions of symmetrical dimethylenebiphenyl dianions; conformations of [O.n]-o-cyclophanes. A simple NMR method for determining twist angles in biphenyls. J Org Chem 1989, 54:311-317.

51. Wallace KJ, Hanes R, Anslyn E, Morey J, Kilway KV, Siegel J: Preparation of 1,3,5-tris(aminomethyl)-2,4,6-triethylbenzene from two versatile 1,3,5-tri (halo-substituted) 2,4,6-triethylbenzene derivatives. Synthesis 2005, 12: 2080-2083.

52. Cadogan JIG, Molina GAA: Simple and convenient deamination of aromatic amines. Org Bio-Org Chem: J Chem Soc Perkin Trans I $1973,541-542$.

53. Shoesmith JB, Slater RH: Polarity effects in the isomeric a-bromoxylenes and isomeric iodotoluenes. J Chem Soc 1924, 125:2278-2283.

54. Kornblum N, Kendall DL: The use of dimethylformamide in the Ullmann reaction. J Am Chem Soc 1952, 74:5782.

55. Ehmer A, Jahr K, Kuschinsky G, Luellmann H, Mutschler E, Wollert U: Cardiac activity of simple bis(guanylhydrazones). Arzneimittel-Forschung 1964, 14:1273-1277.

56. Frisch MJ, Trucks GW, Schlegel HB, Scuseria GE, Robb MA, Cheeseman JR, Montgomery JA Jr, Vreven T, Kudin KN, Burant JC, Millam JM, Iyengar SS, Tomasi J, Barone V, Mennucci B, Cossi M, Scalmani G, Rega N, Petersson GA, Nakatsuji H, Hada M, Ehara M, Toyota K, Fukuda R, Hasegawa J, Ishida M, Nakajima T, Honda Y, Kitao O, Nakai H, Klene M, Li X, Knox JE, Hratchian HP, Cross JB, Bakken V, Adamo C, Jaramillo J, Gomperts R, Stratmann RE, Yazyev O, Austin AJ, Cammi R, Pomelli C, Ochterski JW, Ayala PY, Morokuma K, Voth GA, Salvador P, Dannenberg JJ, Zakrzewski VG, Dapprich S, Daniels AD, Strain MC, Farkas O, Malick DK, Rabuck AD, Raghavachari K, Foresman JB, Ortiz JV, Cui Q, Baboul AG, Clifford S, Cioslowski J, Stefanov BB, Liu G, Liashenko A, Piskorz P, Komaromi I,
Martin RL, Fox DJ, Keith T, Al-Laham MA, Peng CY, Nanayakkara A, Challacombe M, Gill PMW, Johnson B, Chen W, Wong MW, Gonzalez C, Pople JA: Gaussian 03, version Revision B.05. Wallingford CT: Gaussian, Inc; 2004.

57. Boehm S, Gal J-F, Maria P-C, Kulhánek J, Exner O: Steric effects in isolated molecules: gas-phase basicity of methyl-substituted acetophenones. Eur J Org Chem 2005, 2580-2588.

doi:10.1186/1752-153X-6-52

Cite this article as: Titinchi et al:: A reactivity-selectivity study of the FriedelCrafts acetylation of 3,3'-dimethylbiphenyl and the oxidation of the acetyl derivatives. Chemistry Central Journal 2012 6:52.

\section{Publish with ChemistryCentral and every scientist can read your work free of charge \\ “Open access provides opportunities to our colleagues in other parts of the globe, by allowing anyone to view the content free of charge." \\ W. Jeffery Hurst, The Hershey Company. \\ - available free of charge to the entire scientific community \\ - peer reviewed and published immediately upon acceptance \\ - cited in PubMed and archived on PubMed Central \\ - yours - you keep the copyright \\ Submit your manuscript here: \\ http://www.chemistrycentral.com/manuscript/}

